\title{
Correction to: Once-Monthly Long-Acting Injectable Aripiprazole for the Treatment of Patients with Schizophrenia and Co-occurring Substance Use Disorders: A Multicentre, Observational Study
}

\author{
Nestor Szerman ${ }^{1}$ (D) - Ignacio Basurte-Villamor ${ }^{1}$ (D) - Pablo Vega ${ }^{2}$ D . Jose Martinez-Raga ${ }^{3}$ - Carlos Parro-Torres ${ }^{4}$. \\ Julia Cambra Almerge ${ }^{5}$ D $\cdot$ Lara Grau-López $^{6}$ (D) Mario De Matteis $^{4}$ (D) Francisco Arias $^{7}$ (D)
}

Published online: 28 February 2020

(c) The Author(s) 2020

\section{Correction to: Drugs - Real World Outcomes https://doi.org/10.1007/s40801-020-00178-8}

Page 5, Discussion section, column 2, line 11. The following sentence that previously read:

"A randomized, 1-year follow-up study comparing LAI aripiprazole with LAI paliperidone in patients with psychosis, mostly schizophrenia, and SUD reported a large effect of the change from baseline in the CGI severity score, from 5.9 to 2.4 for LAI aripiprazole and from 5.7 to 2.6 for LAI risperidone [29]".

should read:

The original article has been updated. The corrected publication can be found online at https://doi.org/10.1007/s40801-020-00178 -8 .

Nestor Szerman

nszermanb@gmail.com

1 Instituto Psiquiatría y Salud Mental, Hospital General Universitario Gregorio Marañón, Calle de Lope de Rueda, 43, 28009 Madrid, Spain

2 Instituto de Adicciones, Madrid Salud, Madrid, Spain

3 Psychiatry Department, University Hospital Dr. Peset, University of Valencia and University CEU-UCH, Valencia, Spain

4 Psychiatry Department, Hospital General Universitario Gregorio Marañón, Madrid, Spain

5 Psychiatry Department, "Proyecto Hombre", Madrid, Spain

6 Addiction and Dual Diagnosis Unit, Department of Psychiatry, Vall d'Hebron University Hospital, CIBERSAM, Barcelona, Spain

7 Psychiatry Department, 12 de Octubre University Hospital, Madrid, Spain
"A randomized, 1-year follow-up study comparing LAI aripiprazole with LAI paliperidone in patients with psychosis, mostly schizophrenia, and SUD reported a large effect of the change from baseline in the CGI severity score, from 5.9 to 2.4 for LAI aripiprazole and from 5.7 to 2.6 for LAI paliperidone [29]".

The original article has been corrected.

Open Access This article is licensed under a Creative Commons Attribution-NonCommercial 4.0 International License, which permits any non-commercial use, sharing, adaptation, distribution and reproduction in any medium or format, as long as you give appropriate credit to the original author(s) and the source, provide a link to the Creative Commons licence, and indicate if changes were made. The images or other third party material in this article are included in the article's Creative Commons licence, unless indicated otherwise in a credit line to the material. If material is not included in the article's Creative Commons licence and your intended use is not permitted by statutory regulation or exceeds the permitted use, you will need to obtain permission directly from the copyright holder.To view a copy of this licence, visit http://creativecommons.org/licenses/by-nc/4.0/. 